\title{
Applied Research: Design-Build Studio as Laboratory
}

\author{
A Design-Build program integrated into the curriculum of accredited MArch/ \\ BArch programs at the University of Arizona uses the vehicle of small residential \\ projects to hypothesize and test the efficacy of various wall and roof assemblies \\ against thermal transfer and as thermal mass.
}

\section{INTRODUCTION}

A Design-Build program integrated into the curriculum of accredited MArch/BArch programs at the University of Arizona uses the vehicle of small residential projects to hypothesize and test the efficacy of various wall and roof assemblies against thermal transfer and as thermal mass.

Five prototype dwellings were designed, by students and faculty, for the most common residential lot configurations in Tucson; each with a different thermal strategy for avoiding summer heat gain and/or increasing winter heat gain. While some residences were under construction by a design-build studio, a series of thermal sensors was placed at key locations within the wall and roof assemblies to measure the transfer of heat. A weather station on site recorded the conditions in the immediate microcosm, and all sensors reported to a computer stationed inside the residence under study. The temperature data was recorded every 15 seconds for a full year of inhabitation by homeowners, and then conclusions could be drawn about the performance of the building envelope.

\section{THE DESIGN-BUILD PROGRAM}

A brief overview of the structure and organization of the Design-Build Program at the University of Arizona is useful to explain the ongoing pedagogical goals of the program within the architecture curriculum, the specific project discussed here, the research embedded within the project, and the method of project delivery.

Faculty members and administrators of the College of Architecture, Planning and Landscape Architecture established a corporation called the Drachman Design-Build Coalition in 2004, which was designated as a 501c3 non-profit by the IRS in 2006. This entity was formed in service of the existing design-build program in the college, which sought to design and build affordable housing for the segment of Arizona's population earning below $80 \%$ of the area median income. The objectives of DDBC included the establishment of a standard of design quality that encourages dignity and pride of ownership in dwellers, the provision of hands-on educational opportunities for architecture students to design and construct
MARY C. HARDIN

The University of Arizona 
residential projects from land acquisition to post-occupancy evaluations, and the provision of opportunities for continued education for faculty in order to promote personal and professional growth and development as it pertains to service delivery and public policy. Incorporation as a 501c3 organization allowed DDBC to function as an entity separate from the University, in order to obtain a contracting license, borrow funds for construction, subcontract outside of state bidding regulations, maintain financial independence, obtain grant funding and donations, and qualify as a Community Based Design Center for the purpose of gaining IDP credit for student interns.

All of the projects designed and constructed by DDBC have been community outreach projects, delivered within the framework of a design-build studio, a curricular offering of the UA School of Architecture. Taught by a registered architect and residential contractor, these studios have exposed students to the spectrum of architectural practice, from project inception, client meetings, design and construction documents, to through the construction of each residence to completion and certificate of occupancy. Each residence has taken three semesters to complete; typically one semester spent in design and construction documents and two in construction. Completed residences are sold at cost to first time homebuyers through a HUD homeownership program with strict qualifying requirements.

\section{RESEARCH COMPONENT}

Within this educational framework of design and construction, faculty members found opportunities for research that aligned with the pedagogical and outreach goals of the design-build program. The quest to identify the lowest cost, most thermally efficient products for building wall and roof assemblies for affordable housing led to a research agenda that spanned four of the residential projects. Design guidelines for energy and water conservation were developed before design commenced on the residences, in order to guide faculty and students in decision making with regard to resource efficiency. These guidelines compared all factors known to affect energy and water use in residences in arid climates, and ranked them in terms of efficiency and cost. Using the guidelines for thermal comfort control, the residences were designed to employ insulative strategies, thermal mass strategies, or strategies that combined the two approaches (hybrids). During the design phase, each dwelling was modeled with software that simulated the building envelope and and predicted the annual energy use. During the construction period, thermal sensors were placed at key locations within the wall and/or roof assemblies, and were connected to a local weather station and computer at the time of home occupancy. Temperature, air velocity, and other measures were taken at fifteen second intervals for a year while the home was occupied by the new homeowners. Finally, the actual energy use was compared with the predictions and design revisions were proposed for each dwelling.

\section{DESIGN GUIDELINES FOR ENERGY EFFICIENCY AND WATER CONSERVATION}

The design guidelines that governed the development of the residences designed and constructed by UA design-build studios were compiled and organized by faculty and staff of the college, and were published as a 40 page document that ranked strategies, materials, equipment, and other factors that can affect energy and water efficiency, along with a cost index. These guidelines are available online at http: /capla.arizona.edu/sites/default/files/ faculty_papers/Conservation\%20Guidelines\%20for\%20Affordable\%20Housing.pdf.

\section{PROJECTS}

\section{Flow-Through House}

The first residence in this series of five was designed with an integrated cavity wall along the entire southern façade. The cavity wall was intended to shade the exterior of the actual structural wall and also lessen the daytime heat absorption of the most exposed wall by the 

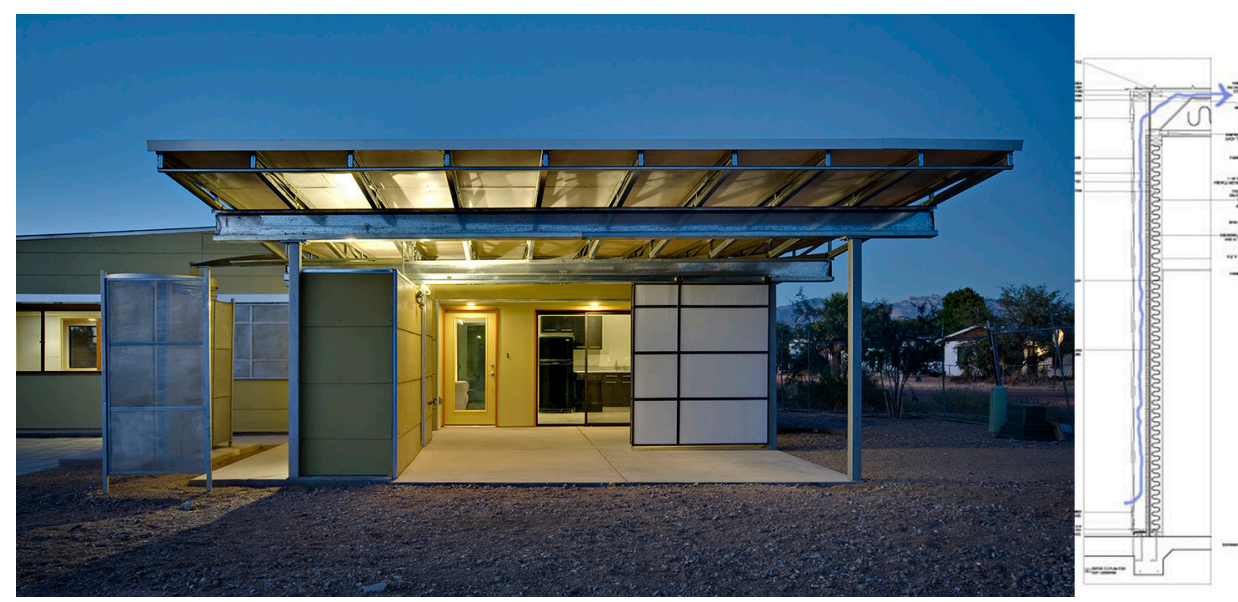

use of thermal convection through the cavity. Flow-Through House is a single story, threebedroom house with 1072 square feet of conditioned space. The long axis of the house runs east-west, which takes best advantage of solar orientation for passive solar considerations. The wood framed south wall is designed to function as a thermal break, with a 3.5 inch cavity that is vented near the bottom and top of the wall. Foil-backed rigid insulation was layered over the exterior of the structural $2 \times 4$ wall (thus facing south within the cavity) and the exterior of the $2 \times 4$ cavity wall was clad with fiber cement panels (perforated near the bottom and top).

The energy performance of this house design was simulated in ENERGY-10 software, which predicted an overall energy savings of $5.8 \%$ with the incorporation of a south-facing vented cavity wall. The simulation showed slightly higher heating loads due to the flushing of heat from the cavity in winter months, but a significantly reduced cooling load during the rest of the year.

The inhabited house was monitored for a one year period, using a central weather station installed on an outbuilding near the residence that collected data on the microclimate, and several sensors measuring temperature and air movement around and within the cavity wall. The results of the data collected verified the design hypothesis for this residence. During the daytime in the hottest summer months, the cavity wall did act as a shading device for the structural wall (reducing the air temperature inside the cavity wall by up to $40 \%$ ) and the convective air loop within the cavity brought air into the cavity that was an average of 12 degrees cooler than the exiting air. As predicted, the cavity wall did not contribute to energy savings during the cold months. If the cavity wall were redesigned with operable inlet vents, the cavity could be used for heat gain during the winter.

The total cost of the electricity used for the year the house was monitored was $\$ 965$. This compares favorably to the Tucson average of $\$ 1440$ per year per household. The addition of the vented cavity wall cost $\$ 80$ in extra materials. The energy savings that could be attributed to the vented cavity wall for the year the house was monitored were $\$ 60,61$. In less than two years, the savings paid back the cost of the extra materials.

\section{Armadillo House}

The second residence was designed as a super-insulated light gauge steel and steel panel clad envelope penetrated by small courtyards for natural ventilation. Armadillo House is a single story, three-bedroom house with 1200 square feet of conditioned space. The long axis of this house runs north-south, due to the orientation of the parcel. Because the east and west walls are best suited for insulation rather than apertures, two small courtyards were used to break up the building mass and allow more north and south facades for window

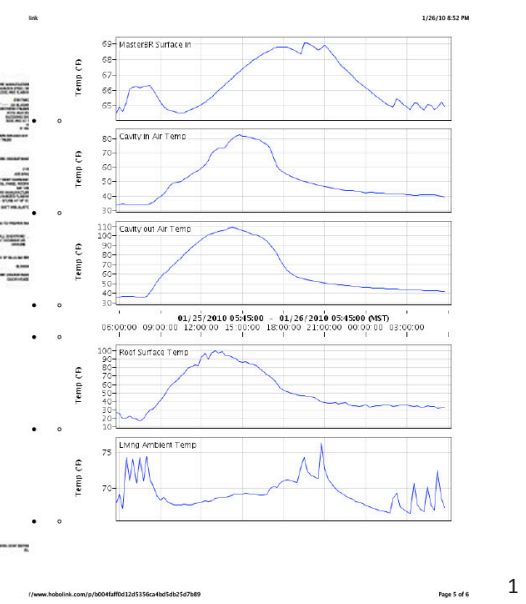

Figure 1: low-Thru House; Insulative wall assembly with vented cavity wall section and data output. (Photo: Liam Frederick) 


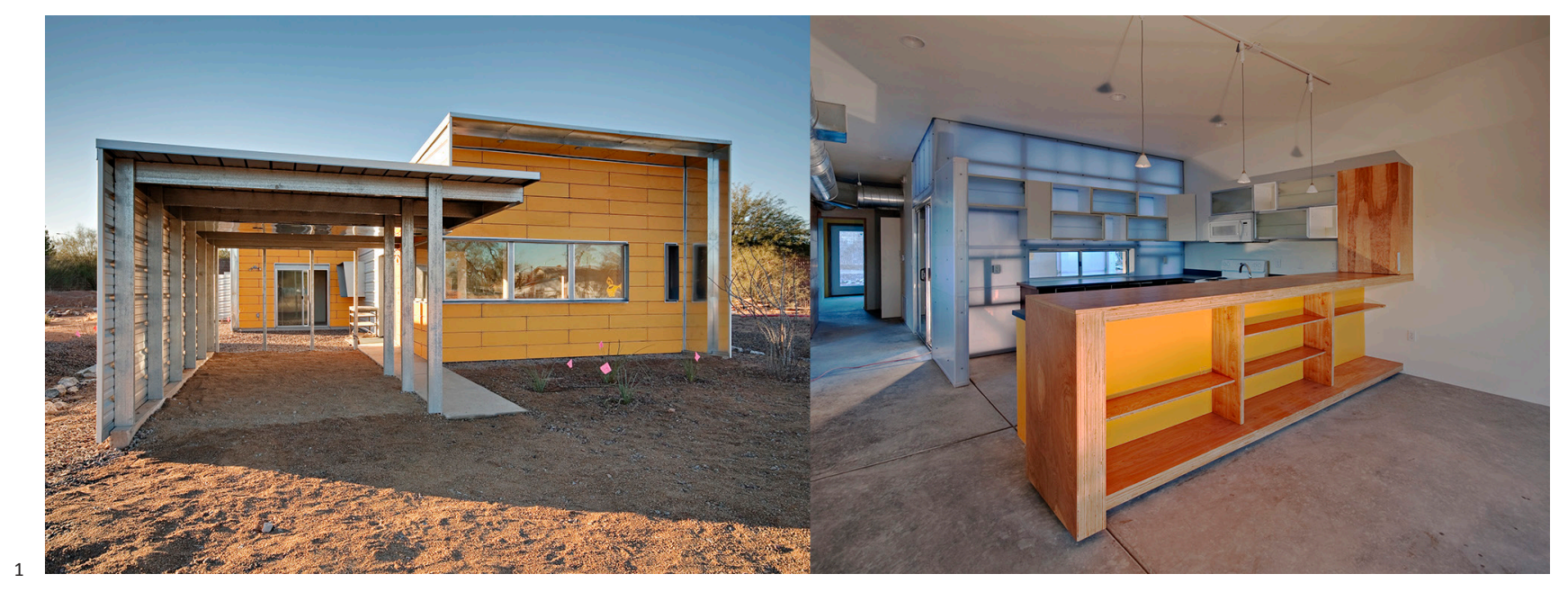

and door openings. The courtyards also allowed for natural ventilation through all rooms of the house, and therefore less reliance upon mechanical cooling. The building envelope was engineered to allow a four feet framing bay, rather than the usual two feet bay used under the prescriptive building code. This reduced thermal bridging by a significant amount, and then rigid foam insulation was installed between the face of all framing members and the metal panels that clad the structure. Blown-in fiberglass insulation as used to achieve values of R-42 in the roof assembly and R-28 in the wall assemblies.

This house was not monitored with the weather station and thermal sensors, due to a timing conflict with the use of the equipment. However, the actual energy use data (22,600 BTU/ sq.ft./year in 2013 and 21,832 BTU/sq,ft./year in 2014) can be compared with the simulated energy use estimate $(30,425 \mathrm{BTU} / \mathrm{sq}$.ft./year). The energy use for this house is $60-62 \%$ of the average in Tucson, representing approximately $\$ 571$ in annual savings on electric bills for this household (\$868.60 per year compared to $\$ 1440$ per year for a household with average energy use).

\section{House with Light Spine}

The third residence is a hybrid design that combines thermal mass with insulation. This is achieved through the use of a custom Concrete Masonry Unit (Integra Block) with wide cavities and no end webs, that is post-tensioned and filled with an expanding foam insulation. Because there are few thermal bridges in this system, the wall assembly gives a value $\mathrm{R}-25$ thermal resistance. House with light Spine is a three-bedroom residence with 1200 square feet of conditioned space. The long axis of the house runs east-west; ideal for the passive solar strategy that emphasizes winter heat gain. The window and door openings were located to take advantage of winter sun angles, which bring direct solar gain to the interior surface of the exposed concrete masonry units and concrete floor slab. The interior thermal mass serves to stabilize the interior temperature of the residence, while the exterior thermal mass radiates accumulated heat back to the night sky once the sun sets. The foam insulation barrier between the exterior and interior thermal masses prevents thermal transfer from outside in. A clerestory strip of polycarbonate glazing tops the circulation corridor that runs the length of the residence, bringing northern light into the hallway and public spaces.

Figure 2: Armadillo House; Insulative This house was monitored for one year while inhabited, and the resulting data demonstrates a significant reduction in heating costs during the winter. There was little difference in thermal performance from an insulative design in the summer months, however. The interior thermal mass walls served to stabilize the interior temperature, but did nothing 

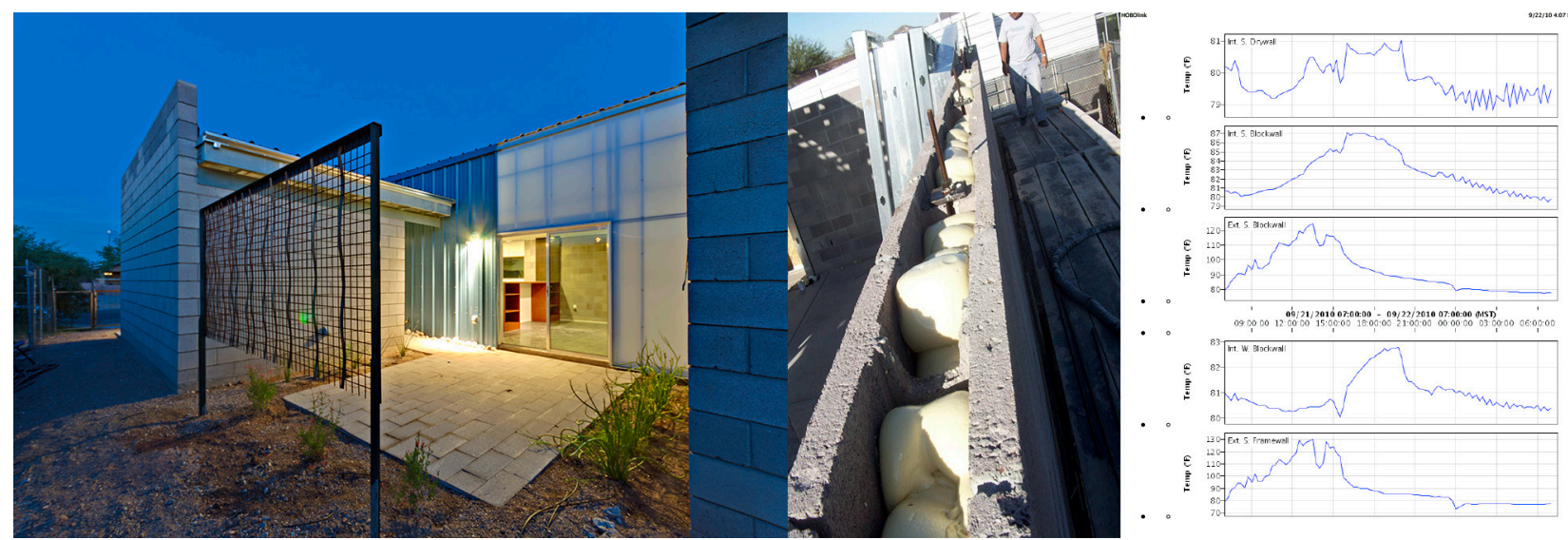

to reduce air conditioning needs. The computer simulation of this design showed summer energy savings if the house was ventilated during nighttime hours. In practice, however, the family occupying the house did not open windows at night due to concerns about security. These results illustrate the need for other design parameters to work in concert with thermal goals (designing a secure aperture for nighttime ventilation, for example), as well as the importance of homeowner education.

\section{Split House}

The fourth residence is also a hybrid design that combines thermal mass walls with insulative walls. In this instance, the long axis of the house is north-south, making it more difficult to place much thermal mass for winter gain. The thermal mass walls are placed as the east and west walls, are constructed of rammed earth, and are 18 inches thick. They are exposed to direct sunlight for only a few hours per day, so these walls have been effective at preventing heat transfer to the interior of the residence. The north and south façades are wood framed walls, insulated to the code requirement of R-19. All of the windows and doors are grouped onto the north and south façades, and this allows them to be adequately shaded from solar gain in the summer but to receive direct sunlight onto interior concrete floors during the winter months. The split volumes of the residence also allow for some selfshading, when one offset volume casts a shadow upon the other.

The electricity used in the Split House was 7,226 kWh during the first year of inhabitation (at a cost of \$926.17), and 8,308 kWh during the second year (at a cost of 1,091.91). This represents $57 \%$ of the average household energy use in Year 1, and $65 \%$ of the average household energy use in Year 2 , for savings of $\$ 514$ and $\$ 348$, respectively.

Figure 3: House with Light Spine; hybrid Integra Block wall system with data output. (Photo: Liam Frederick)

Figure 4: plit House; hybrid rammed earth thermal mass and insulative framed walls. (Photo: Liam Frederick)

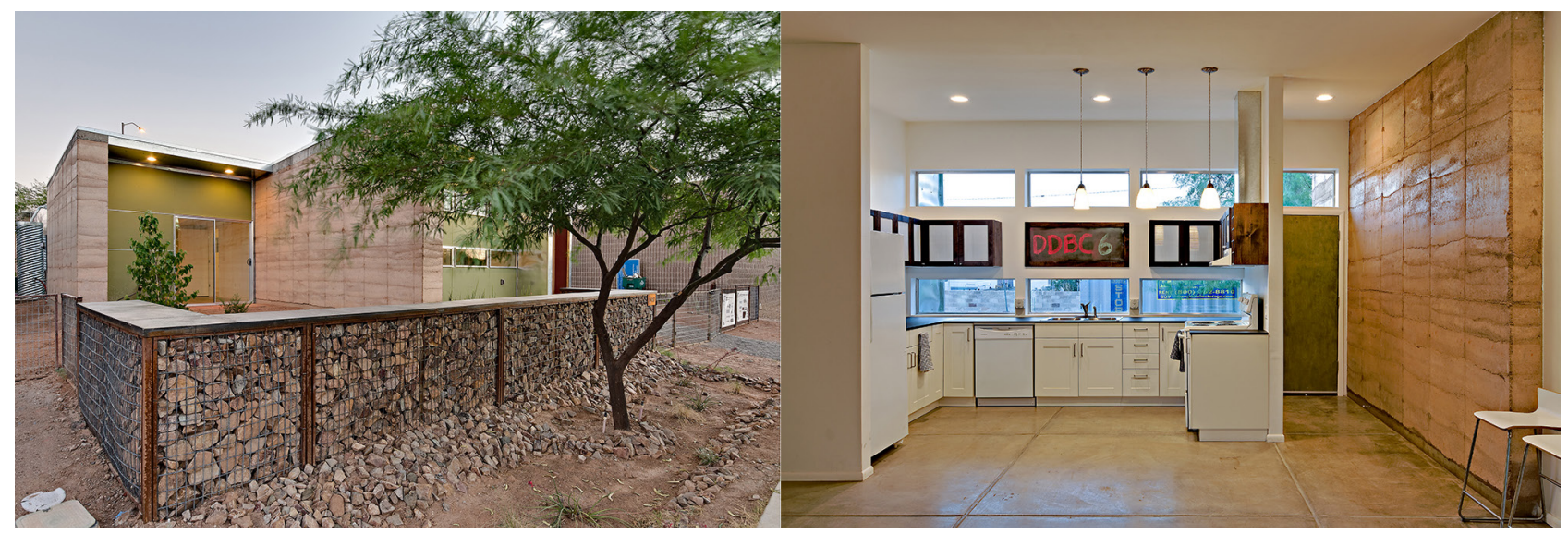




\section{Trombe Wall House}

The fifth house in this series of design-build research projects is also a hybrid system; this time employing an ICF system on the east, west and north with a masonry thermal mass trombe wall on the south. The ICF walls are a proprietary system called "Mikey Block" produced in Tucson, AZ. The 12 inch by 48 inch expanded polystyrene foam blocks have 2 $3 / 4$ inch sides with a 5 inch cavity that holds rebar and gets filled with concrete. The reported $\mathrm{R}$-value for this system is R-28. The ICF walls are clad with Tyvek and corrugated steel panels on the exterior, and drywall on the interior.

The trombe wall is actually comprised of two types of trombe wall designs. The classic trombe wall is a CMU wall, grouted solid and faced with glass, with a 4 inch air cavity between the glass and the CMU. There are operable air vents in the CMU wall that allow heated air into the interior of the house on winter days, and close it off on warm days. There are operable vents at the top of the air cavity to allow heated air to escape to the exterior of the home on warm days. The other type of trombe wall is a glass wall with a 38 hallway between the glass and the solid grouted CMU wall. This modified type of trombe wall relies upon winter heat gain to the concrete slab floor as well as the CMU wall, and is ventilated by the movement of air through the hallway (driven by the mechanical system within the house or by the ceiling fans). The two trombe walls sit side by side, facing south, with a roof overhang that controls direct solar exposure. The classic trombe wall requires the homeowners to operate it while the modified trombe wall does not.

This house has been inhabited for less than a year, but data has been gathered for several months, but has not yet been analyzed. The expectation is that the trombe walls will contribute more to reducing heating costs than reducing cooling costs. This is a design that requires homeowner education, and depends upon manipulation of the vents to achieve the ideal conditions.
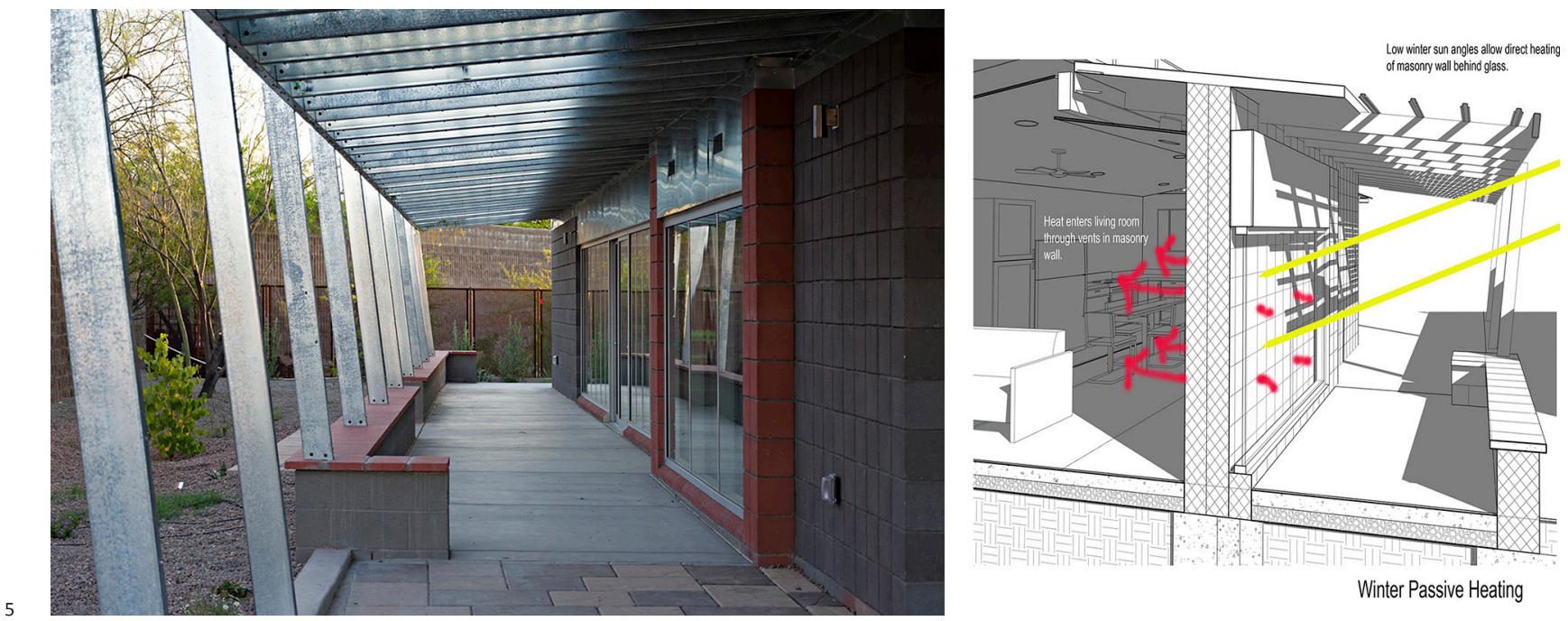

Figure 5: Trombe Wall House; hybrid wall system with trombe wall diagram. (Photo: Liam Frederick)

\section{CONCLUSIONS}

The design-build program at the University of Arizona provides for more than hands-on educational opportunities and community outreach experiences for the students in the School of Architecture. It also serves as a field-testing vehicle for design hypotheses of many kinds. Some of the hypotheses involve explorations of materials and materials assemblies, cost relationships between materials and maintenance requirements, relationships between landscaping design and water use, and relationships between materials assemblies, solar orientation, and energy use. This kind of applied research differs from laboratory testing, 
where the small-scale assemblies are isolated from any other factors such as human use and flaws in workmanship. With the design and construction of actual dwellings that are inhabited by unique homeowners, there are many variables that cannot be quantified precisely. However, the conditions of construction and inhabitation of the design-build dwellings are similar to what happens all over the region in the production and inhabitation of standard housing stock and so allow monitoring of common circumstances - a small percentage of irregularities in workmanship that can affect the efficiency of the building envelope with regard to thermal bridging, and inconsistencies in human behavior that can affect the optimal use of thermostat settings, operable shading elements, use of natural ventilation, etc.

Preliminary evaluations of the data indicate where design improvements should be made, and when homeowner education would benefit the building performance. Recommendations developed from these data has been shared in public workshops with other residential builders, and Industry partners involved in the provision of building materials have expressed a strong interest in the results of this applied research, because they can use it to more accurately promote the value of their products and to give specific advice to architects and contractors. The City of Tucson has ownership of the approved plan sets for the prototype dwellings, and has held two public workshops to disseminate the results to builders and housing officials. Also, the design guidelines that were developed for this research have been disseminated publicly and have a potentially significant impact on collective building performance if they are put into practice for mass produced housing.

Similar to what happens all over the region in the production and inhabitation of standard housing stock and so allow monitoring of common circumstances - a small percentage of irregularities in workmanship that can affect the efficiency of the building envelope with regard to thermal bridging, and inconsistencies in human behavior that can affect the optimal use of thermostat settings, operable shading elements, use of natural ventilation, etc.

Preliminary evaluations of the data indicate where design improvements should be made, and when homeowner education would benefit the building performance. Recommendations developed from these data has been shared in public workshops with other residential builders, and Industry partners involved in the provision of building materials have expressed a strong interest in the results of this applied research, because they can use it to more accurately promote the value of their products and to give specific advice to architects and contractors. The City of Tucson has ownership of the approved plan sets for the prototype dwellings, and has held two public workshops to disseminate the results to builders and housing officials. Also, the design guidelines that were developed for this research have been disseminated publicly and have a potentially significant impact on collective building performance if they are put into practice for mass produced housing.

\section{ENDNOTES}

1. Chalfoun, Nader and Hardin, Mary. (2007) "Conservation Technologies for Affordable Housing: Energy Efficiency and Water Conservation Guidelines, 2007". Drachman Institute, College of Architecture, Planning, and Landscape Architecture, University of Arizona. Published as a 40 page document that ranked strategies, materials, equipment, and other factors that can affect energy and water efficiency, along with a cost index, available online at http: /cala.arizona.edu/sites/default/files/faculty_ papers/Conservation\%20Guidelines\%20for\%20 Affordable\%20Housing.pdf

2. Chalfoun, N.V. (2011) "Investigating the Role of Exterior Cavity Walls in Improving Building Envelope Thermal Performance through Real-time Data Monitoring and Simulation", American Solar Energy Society (ASES) National Solar Conference, May $17-21,2011$, Raleigh, North Carolina.

3. Residential electricity consumption in Arizona averages 1,061 kWh/month; 12,732 kWh/year. 2015 Electricity Local, http: /www.electricitylocal. com/states/arizona/tucson/ 